\title{
Effects of Daphnia Availability on Growth and Food Consumption of Rainbow Trout in Two Utah Reservoirs
}

\author{
ROGER TABOR ${ }^{1}$ \\ Utah Cooperative Fish and Wildlife Research Unit \\ Department of Fisheries and Wildlife, Utah State University \\ Logan, Utah 84322-5210, USA
}

Chris Luecke and Wayne Wurtsbaugh

Department of Fisheries and Wildlife, Ecology Center, Utah State University

\begin{abstract}
We monitored the diet and growth of stocked rainbow trout Oncorhynchus mykiss in two Utah reservoirs during 1986 and 1989-1990. For the first month after stocking, juvenile rainbow trout in both reservoirs fed extensively on large Daphnia spp. In East Canyon Reservoir where Daphnia were abundant, this pattern continued throughout the summer, fall, and winter. Growth of rainbow trout in East Canyon Reservoir was generally good throughout 1989-1990. In Causey Reservoir, where Daphnia were less abundant and smaller, rainbow trout fed progressively less on smaller Daphnia throughout the summer, fall, and winter, while other prey items (snails, aquatic insects, and algae) became more important. Bioenergetics simulations of patterns of rainbow trout growth suggest that consumption by rainbow trout was closely related to daphnid biomass. This index of zooplankton forage could be used to assess feeding conditions for zooplanktivorous salmonids in other systems.
\end{abstract}

Zooplankton are known to be important prey for many species of salmonids. Galbraith (1967), Hyatt (1980), Eggers (1982), and Schneidervin and Hubert (1987) have demonstrated that large-bodied zooplankton, especially Daphnia spp., can compose a substantial portion of the diet of lakedwelling Oncorhynchus spp. In spite of the recognized importance of these prey resources, few investigators have examined the extent to which variation in the density and size structure of zooplankton affects the consumption rates and resultant growth of these planktivorous fishes.

For rainbow trout $O$. mykiss in lentic systems, Galbraith (1975) suggested that the density of zooplankton longer than $1.3 \mathrm{~mm}$ provides a good index of food availability. English (1983) also found a strong relation between growth of juvenile chinook salmon $O$. tshawytscha and the abundance of large zooplankton (i.e., $>1.4 \mathrm{~mm}$ ). For planktivorous percids, mean zooplankton length has been positively correlated with fish growth (Mills and Schiavone 1982) and total yellow perch Perca flavescens biomass (Post and McQueen 1987).

Correlations between fish growth and prey abundance are complicated because fish growth is affected by fish size, temperature, and other factors

${ }^{1}$ Present address: U.S. Fish and Wildlife Service, Western Washington Fishery Resource Office, 2625 98502, USA. in addition to food availability. We avoided some of these complications in our study by using bioenergetics simulations of fish growth to account for effects of variable fish size and water temperature. We compared the abundance of daphnids to the proportion of maximum consumption ( $P$-value) achieved by fish in our bioenergetics simulations. This $P$-value takes into account fish size and water temperature and can be used as an index of consumption that can be compared to food availability in the environment.

We examined how variation in zooplankton prey resources affected consumption and growth of rainbow trout in two Utah reservoirs. We then used a bioenergetics model (Hewett and Johnson 1987) to estimate consumption, given observed growth of rainbow trout. Finally, estimates of consumption rates from energetics simulations were regressed against estimated zooplankton biomass to provide a predictive relation between zooplankton biomass and growth for rainbow trout under natural conditions.

\section{Methods}

We examined zooplankton levels, water temperature, and growth of stocked rainbow trout in two northern Utah reservoirs. The Utah Division of Wildlife Resources stocks each reservoir annually with juvenile rainbow trout. East Canyon Reservoir is a 277 -ha impoundment at $40^{\circ} 54^{\prime} 20^{\prime \prime} \mathrm{N}$, $111^{\circ} 35^{\prime} 20^{\prime \prime} \mathrm{W}$ at an elevation of $1,734 \mathrm{~m}$ and has 
a mean depth of $23 \mathrm{~m}$ and $16 \mathrm{~km}$ of shoreline. Water residence time is approximately 1.1 years. East Canyon Reservoir is meso-eutrophic with abundant large Daphnia that allow juvenile rainbow trout to grow at or near maximal rates (Marine et al. 1986; Wurtsbaugh et al. 1996). We sampled zooplankton and rainbow trout during May-November 1986 and May 1989-April 1990. In May 1986 and May 1989, the reservoir was stocked with 300,000 rainbow trout (mean weight, $5.3 \mathrm{~g}$; standard length, SL, about $70 \mathrm{~mm}$ ). Fish stocked in 1986 were marked with fluorescent grit dye (Phinney et al. 1967). No marks were used in 1989; however, fish could readily be separated from other cohorts by length-frequency analysis.

The second field site, Causey Reservoir, has an area of 58 ha. This mesotrophic reservoir is at $41^{\circ} 17^{\prime} 55^{\prime \prime} \mathrm{N}$ and $111^{\circ} 35^{\prime} 13^{\prime \prime} \mathrm{W}$ at an elevation of $1,735 \mathrm{~m}$ and has a mean depth of $20 \mathrm{~m}$ and 11.8 $\mathrm{km}$ of shoreline. Water residence time is approximately 0.8 years. Zooplankton are abundant, but densities of large Daphnia are usually lower than in East Canyon Reservoir (Tabor and Wurtsbaugh 1991). The Utah Division of Wildlife Resources stocked the reservoir on May 15, 1989, with 61,000 rainbow trout (mean weight, $5.7 \mathrm{~g}$; mean $\mathrm{SL}, 70 \mathrm{~mm}$ ). These fish were also later identified by length-frequency analysis.

Rainbow trout were sampled approximately monthly with variable-mesh gill nets. Nets were set in the evening and retrieved 2-3 h later or the following morning. Fish were placed on ice, and fish weights and standard lengths were measured within approximately $4 \mathrm{~h}$. Growth of the stocked cohort was estimated from changes in mean wet weight. Specific growth rates (\% increase/d) were also calculated (Busacker et al. 1990). Stomach contents of rainbow trout were visually inspected to estimate the relative proportion (nearest $5 \%$ by volume) of major food items for each fish. The percentages of Daphnia from all fish were totaled to estimate the mean percentage of Daphnia in the diet. Samples were preserved in ethanol for zooplankton analysis. To estimate the mean size of zooplankton ingested, we randomly selected 10 rainbow trout stomachs and measured the lengths of the first 10 zooplankters encountered from each stomach. Cladocerans were measured from the top of their heads to the base of their tail spine. Measurements were taken with an ocular micrometer to the nearest $0.034 \mathrm{~mm}$.

Zooplankton was collected approximately every 3-5 weeks after rainbow trout were stocked. Zooplankton samples were always collected on the day fish were sampled. Additional zooplankton sam ples were collected on dates when other field sampling was undertaken. One to three vertical $z_{00}$ plankton tows of the entire water column were made with a $30-\mathrm{cm}$-diameter plankton net (153. $\mu \mathrm{m}$ mesh). Density calculations did not include an estimate of net efficiency. Samples were collected during daytime, usually in the afternoon (1300 1600 hours), at one offshore site near the dam in each reservoir. Zooplankton was preserved with Lugol's solution, identified to species, and enumerated. The first 20-60 Daphnia spp. encountered were measured to the nearest $0.034 \mathrm{~mm}$ with an ocular micrometer. Dry weights $(W, \mathrm{mg})$ of individual daphnids were calculated from lengths $(L$, $\mathrm{mm}$ ) with the following formulas (adapted from McCauley 1984): D. galeata, $\log _{e} W=-4.83+$ $2.53 \log _{e} L ; D$. schodleri and D. pulex, $\log _{e} W=$ $-5.04+2.83 \log _{e} L$.

Consumption rates of rainbow trout were estimated with a bioenergetics model (Hewett and Johnson 1987). Inputs to the model were water temperature, fish body weight, and the change in mean weight of identified cohorts of rainbow trout over different time intervals. We used model parameters from a general model for Oncorhynchus (Hewett and Johnson 1987), but modified the respiration function intercept by using rainbow trout data from Wieser (1985). This modification resulted in an $8 \%$ decrease in respiration rates applied to the general model. Parameter RA (Hewett and Johnson 1987) was changed from 0.00264 to 0.002076 . Energy density of Daphnia prey was assumed to be $3.77 \mathrm{~kJ} / \mathrm{g}$ wet weight (Luecke and Brandt 1993). For the rest of the diet, which included insects, snails, and other prey, we used a value of $3.35 \mathrm{~kJ} / \mathrm{g}$ wet weight (adapted from Cummins and Wuycheck 1971).

Temperature profiles were measured approximately monthly in each reservoir after fish were stocked. Temperatures selected by rainbow trout were estimated from vertical gill-net samples from at East Canyon Reservoir, May to August, 1986 and 1987 (W. Wurtsbaugh, unpublished data). After the fish were stocked, they inhabited shallow water in the littoral zone (Tabor and Wurtsbaugh 1991) until they reached 100-120 mm SL and then moved offshore to the pelagic zone. During summer when the reservoir was stratified, rainbow trout inhabited the metalimnion at approximately $18-19^{\circ} \mathrm{C}$. Estimates of food consumption from model simulations were used to examine the relation between consumption and available $\mathrm{zoO}^{-}$ plankton biomass between reservoirs and at dif- 

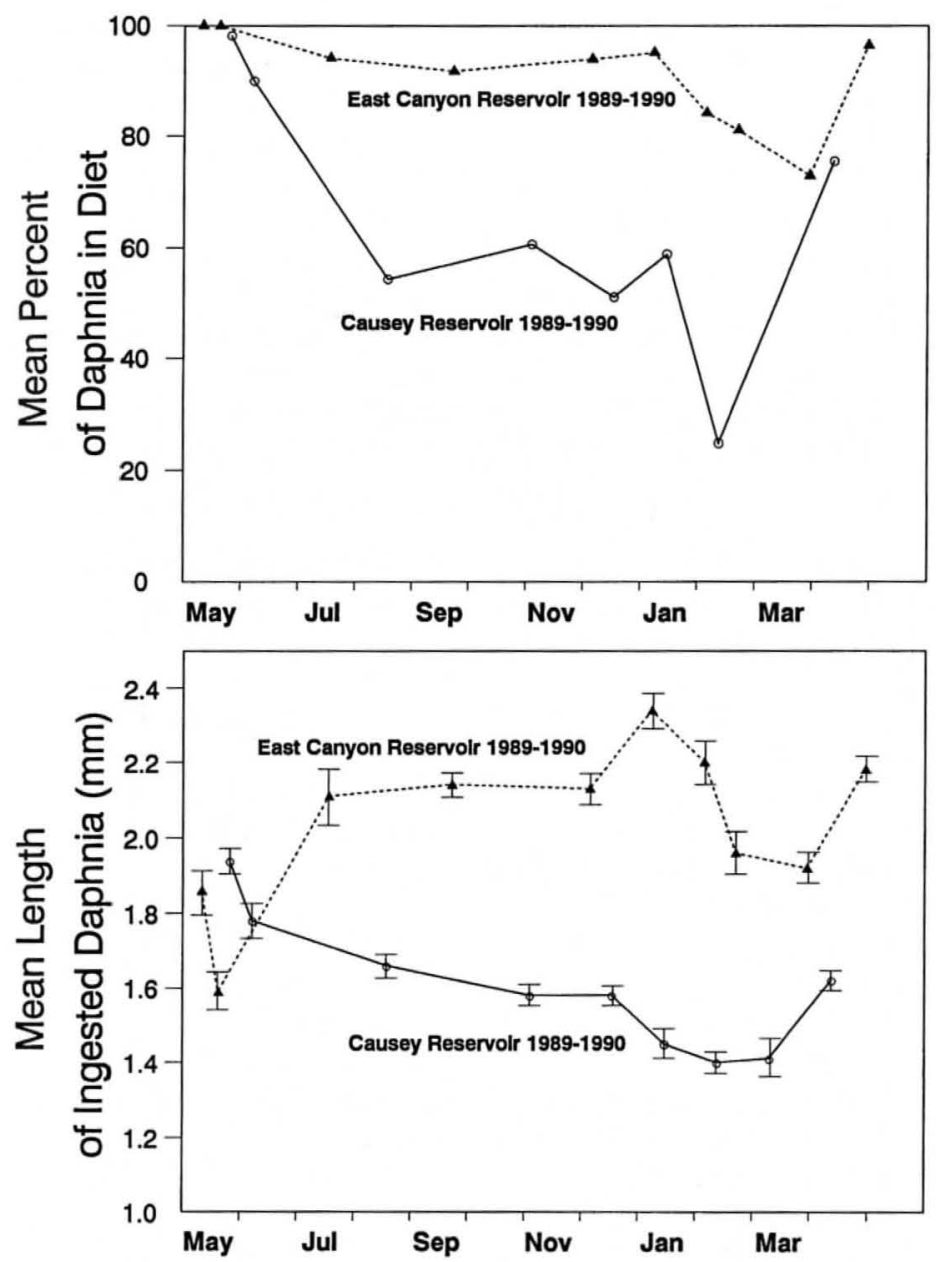

FIGURE 1.-Mean percent by volume of Daphnia spp. present in rainbow trout stomachs and mean length $( \pm 2$ SE) of ingested Daphnia. Samples were taken from May 1989 to April 1990 at East Canyon and Causey reservoirs.

ferent times of the year. We expressed consumption as a proportionality constant of maximum ration ( $P$-value, as in Hewett and Johnson 1987). We regressed $P$-values on mean zooplankton abundance for each time interval in which fish growth was estimated. Several measures of Daphnia size and abundance were used in the regression analysis: number per liter, mean length, and biomass.

\section{Results}

Throughout the year, Daphnia spp. were the predominant prey of rainbow trout in both reservoirs (Figure 1). In East Canyon Reservoir, rainbow trout fed extensively on 1.5-2.5-mm Daphnia (Figure 1). These rainbow trout consumed approximately $95 \% \mathrm{D}$. pulex and $5 \% \mathrm{D}$. schodleri. Aquatic and terrestrial insects were preyed on dur- ing the summer and fall, but they composed only a small fraction of the diet. Daphnia ingested by rainbow trout in Causey Reservoir were generally smaller than those eaten in East Canyon Reservoir, and their size declined throughout most of the year from 1.9 to $1.45 \mathrm{~mm}$. The Daphnia ingested were D. pulex (58\%), D. schodleri $(20 \%)$, and D. galeata (22\%). As Daphnia became progressively less important to rainbow trout in Causey Reservoir, snails, aquatic and terrestrial insects, tubificid worms, and algae became more important. Small rocks and pieces of wood were also present in many rainbow trout stomachs.

Growth of rainbow trout in East Canyon Reservoir was generally good throughout the 19891990 sampling period (Figure 2). Growth rate was highest in May 1989 and lowest in April 1990. 

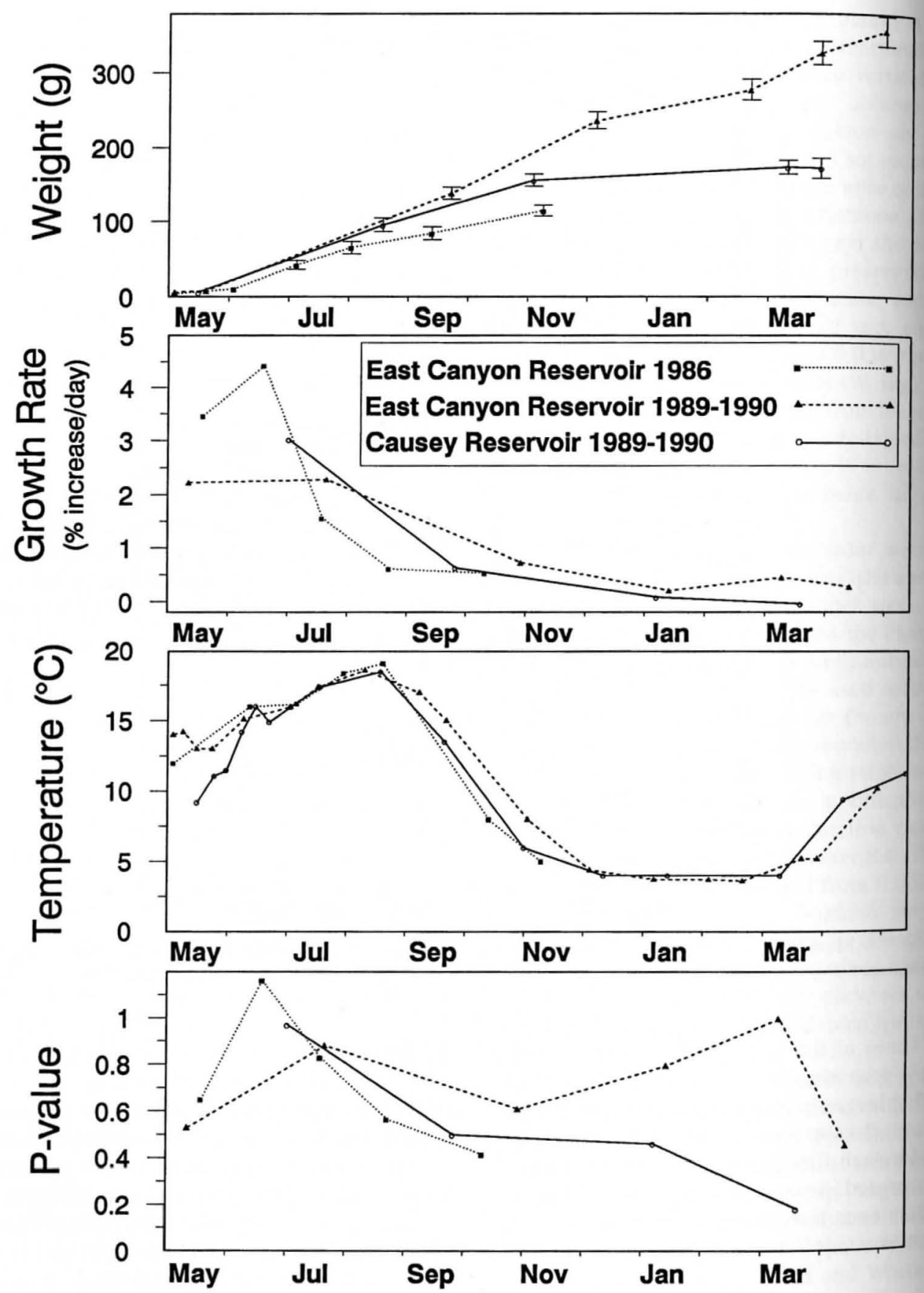

FIGURE 2.-Mean wet weights ( $\pm 2 \mathrm{SE})$, specific-growth rates (\% increase/d), estimated water temperatures $\left({ }^{\circ} \mathrm{C}\right.$ ) inhabited by rainbow trout, and $P$-values from bioenergetics simulations of rainbow trout in East Canyon Reservoir (1986 and 1989-1990) and Causey Reservoir (1989-1990). Values for growth rates and $P$-values represent the midpoint between two consecutive sampling dates shown in the top graph. Water temperatures at which rainbow trout were found were based on prior vertical gill-net samples from East Canyon Reservoir. The $P$-values represent the proportion of maximum ration consumed by the fish and range from 0 to 1.0; a value of 1.0 represents a fish feeding at its maximum rate; a value above 1.0 represents some type of field or model error. 

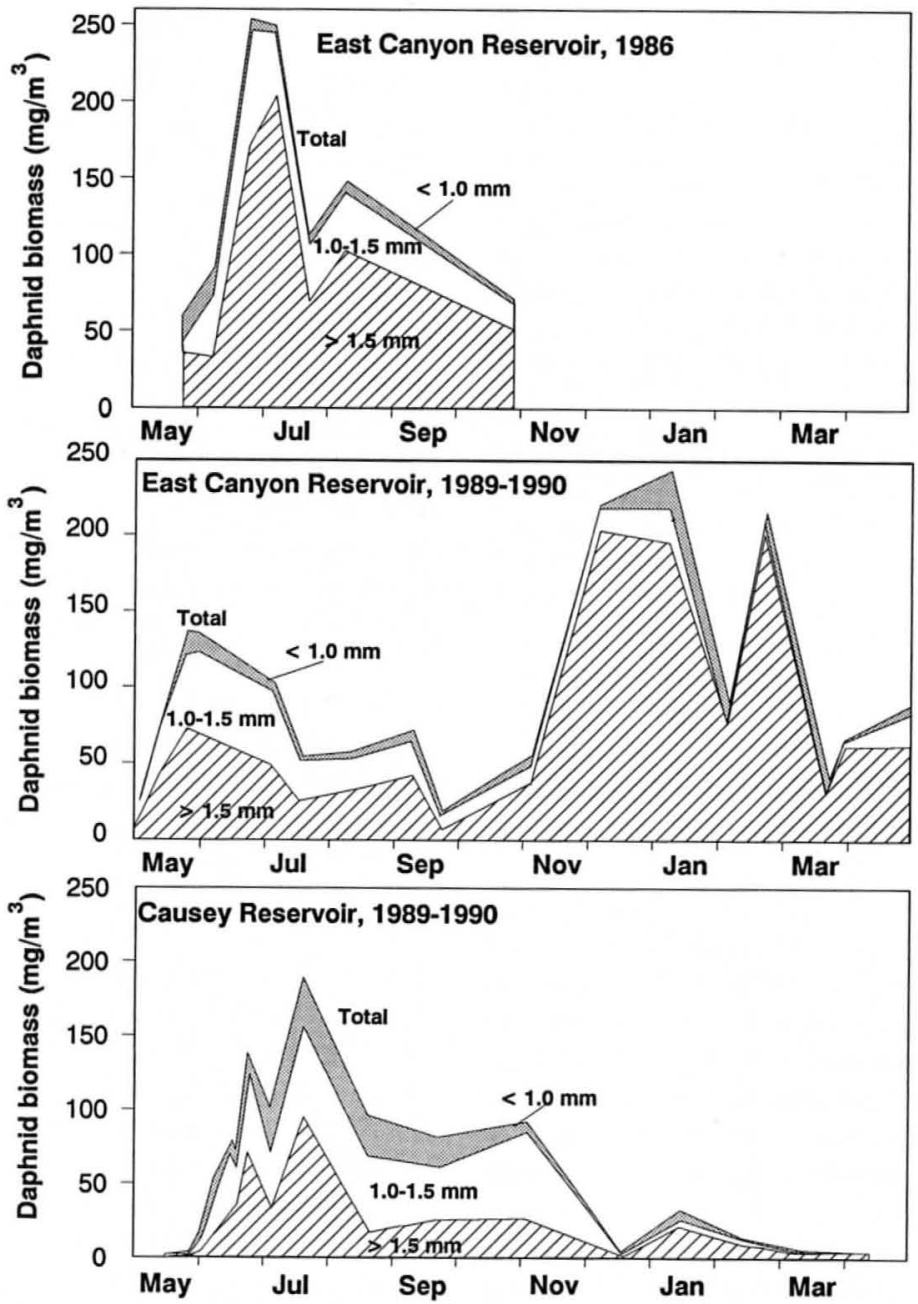

FIgURE 3.- Total dry biomass of Daphnia spp., divided into three size-classes, collected with vertical zooplankton hauls in Causey Reservoir (1989-1990) and East Canyon Reservoir (1986 and 1989-1990). Values represent the mean of one to three samples taken at the same offshore site where depths sampled were $21-40 \mathrm{~m}$.

The bioenergetics model indicated that rainbow trout were feeding at $45-100 \%$ of their maximum ration (Figure 2). Growth rates in 1986 followed similar trends, high in May and June and low in August and September (Figure 2). However, overall growth in 1986 was substantially slower than growth in 1989 (Figure 2), even though Daphnia levels remained higher in 1986 (Figure 3). In part, this may have been due to cooler water temperatures in September and October 1986 than in 1990 but may have also been due to other environmental factors. During August and September, high epilimnetic temperatures and low oxygen levels in the hypolimnion can squeeze rainbow trout into a narrow thermocline. These fish are also often heavily parasitized by Lernaea cyprinacea (Babey and Berry 1989).

During 1989-1990, the growth of rainbow trout in Causey Reservoir was high in May-August but was substantially lower in September-October. Rainbow trout growth was minimal in NovemberMarch. This pattern was in contrast to higher growth of rainbow trout in East Canyon Reservoir in November-March (Figure 2).

The biomass of daphnids increased in both reservoirs during May (Figure 3). In East Canyon Reservoir, daphnid biomass peaked in late June 1986 and remained relatively high throughout July-October (Figure 3). In East Canyon Reservoir, 1989-1990, daphnid biomass declined during 
TABLE 1.-Relation between abundance, size, and biomass of daphnids $(X)$ and rainbow trout $P$-values $(Y)$ from combined East Canyon Reservoir (1989-1990 and 1986) and Causey Reservoir (1989-1990). Daphnid abundance and biomass were divided into four length-classes (total, $>1.0,>1.3$, and $>1.5 \mathrm{~mm}$ long). The $P$-values were calculated from bioenergetics simulations. Regression coefficients and $r^{2}$ values are from $Y=a X^{b}$ regressions. Number of data points is 15 in all cases, except mean length of daphnids ingested (10 data points).

\begin{tabular}{lccc}
\hline & \multicolumn{2}{c}{$\begin{array}{c}\text { Regression } \\
\text { coefficient }\end{array}$} \\
\cline { 2 - 3 } Daphnid measurement $(X)$ & $a$ & $b$ & $r^{2}$ \\
\hline Biomass $\left(\mathrm{mg} / \mathrm{m}^{3}\right)$ & & & \\
$\quad$ Total & 0.150 & 0.329 & 0.60 \\
$>1.0$ & 0.229 & 0.242 & 0.56 \\
$>1.3$ & 0.184 & 0.301 & 0.54 \\
$>1.5$ & 0.133 & 0.384 & 0.43 \\
Abundance (number/L) & & & \\
$\quad$ Total & 0.393 & 0.327 & 0.50 \\
$>1.0$ & 0.471 & 0.286 & 0.45 \\
$>1.3$ & 0.513 & 0.316 & 0.51 \\
$>1.5$ & 0.578 & 0.300 & 0.51 \\
Mean length (mm) & 0.499 & 0.827 & 0.07 \\
Mean length of daphnids ingested (mm) & 0.173 & 2.013 & 0.35 \\
\hline
\end{tabular}

July and September and then increased to an annual maximum in December. Daphnid biomass was relatively high during early winter and then declined in March and April. In contrast to East Canyon Reservoir, daphnid biomass in Causey Reservoir peaked in late July, then declined in November, and remained relatively low from December to March.

Regression analyses were used to examine the relation between zooplankton biomass $(X)$ and the proportion of maximum consumption $(Y)$ of the rainbow trout in both reservoirs (Table 1). Curvilinear models, described by the formula $Y=a X^{b}$, provided the best fit of the data. The proportion of maximum rainbow trout consumption ( $P$-value) was related to daphnid biomass for all lengthclasses of daphnids, but it was most closely correlated to the total biomass (Table 1). Restricting the daphnid biomass index to larger individuals did not improve the regression relationship. Neither mean length of available daphnid prey nor mean length of ingested daphnids provided a good prediction for $P$-value of rainbow trout.

This analysis indicated that some measures of daphnid biomass rather than density or size were the best predictors of rainbow trout consumption pattern (Table 1). Total daphnid biomass was the single estimate of daphnid prey that explained the greatest portion of the variation in rainbow trout consumption.

\section{Discussion}

In many areas of aquatic ecology, efforts to predict productivity have relied heavily on correlation analysis between adjoining trophic levels. For example, phytoplankton biomass or production is often successfully predicted as a function of phos. phorus or nitrogen concentrations (Vollenweider 1976), and zooplankton production can be modeled as a function of its phytoplankton food resource (Morgan et al. 1980). In fisheries, however, there has been relatively little effort to predict fish production or yield as a function of the proximal prey base, but rather managers have often attempted to use more distantly related trophic or abiotic variables such as lake depth, dissolved solids, phosphorus content or phytoplankton production (Carline 1986). Although zooplankton are relatively easy to measure in lakes, relatively few investigators have attempted to use zooplankton abundance to predict fish growth and production.

Nevertheless, earlier studies (Galbraith 1975; Mills and Schiavone 1982) have demonstrated the value of estimating Daphnia size and abundance in assessing lentic systems for planktivorous fish success. We found a strong relation between biomass of daphnids and an index of rainbow trout consumption ( $P$-value). Total daphnid biomass or biomass of daphnids longer than $1.0 \mathrm{~mm}$ appear to provide a useful index for predicting rainbow trout growth in systems in which Daphnia make up a substantial portion of the fishes' diet. Other measures of zooplankton forage, such as the mean size of cladocerans (Mills and Schiavone 1982) or the number $1.3 \mathrm{~mm}$ or longer per liter (Galbraith 1975) may also be reliable indices for comparisons between lakes with a wide range of productivities. Our data suggest that an index which incorporates the biomass of Daphnia provides a better estimate of food available for planktivorous fish. The advantage of measuring biomass is that the abundance and size of zooplankton are both incorporated in the estimate. Biomass estimates appear to allow for more accurate comparisons of growth conditions between seasons within the same lake and between similar lakes.

Total daphnid biomass and biomass of daphnids longer than $1.0 \mathrm{~mm}$ gave similar results because the proportion of the daphnid biomass that was from daphnids shorter than $1.0 \mathrm{~mm}$ was generally small (Figure 3). East Canyon and Causey reservoirs are both generally productive and tend to have relatively large zooplankton. Estimating the biomass of Daphnia longer than $1.0 \mathrm{~mm}$ may be 
more appropriate for systems whose daphnid biomass is high but composed primarily of Daphnia shorter than $1.0 \mathrm{~mm}$. Hyatt (1980) portrays rainbow trout as predators that are adapted to prey on large, dispersed prey and poorly adapted to exploit small, morphologically uniform prey (i.e., small zooplankton $<1.0 \mathrm{~mm}$ ). Ware (1972) found that size of individual prey and distance from which they were approached by rainbow trout were strongly correlated. According to equations developed by Kerr (1971), planktivorous fish feed and grow more efficiently on large-bodied rather than small-sized prey. Small Daphnia $(<1.0 \mathrm{~mm})$ have a lower caloric value per unit weight (Richman 1958) and are harder to detect (Confer et al. 1978; O'Brien 1979) than the larger Daphnia. Therefore, rainbow trout may have to switch to alternative prey if Daphnia length falls below a certain critical limit.

In Causey Reservoir during winter and spring, few alternative prey were apparently available, and growth rates of rainbow trout declined when availability of large daphnids was low. The lack of large Daphnia and the common occurrence of algae, small rocks, and pieces of wood in the diet of rainbow trout in Causey Reservoir may indicate that preferred prey items are often in low abundance. Large Daphnia were unavailable for most of the year, and subsequently many rainbow trout switched to larger prey of lower quality. Many rainbow trout ingested large quantities of mollusks (primarily snails, but also some clams). Because the mollusks were usually intact in the large intestine, fish were apparently unable to fully digest them and may obtain little nutrition from an individual mollusk.

Both study reservoirs are managed as put-growand-take fisheries, with anglers harvesting an annual crop of fish, and few rainbow trout remain after their second summer in the reservoir. In East Canyon Reservoir, larger rainbow trout continue to forage extensively on Daphnia. In other systems, however, larger rainbow trout may become largely piscivorous (Beauchamp 1990). Thus, using Daphnia biomass estimates may poorly predict growth of these large rainbow trout. Additionally, Daphnia biomass levels may poorly predict rainbow trout growth in lentic systems where their diet is dominated by epibenthic crustaceans and insects associated with extensive shoreline vegetation (Johannes and Larkin 1961). Estimates of large zooplankton for predicting rainbow trout growth are probably best in medium to large fluctuating reservoirs such as the ones studied, or in large lakes where small rainbow trout (i.e., $<250 \mathrm{~mm}$ fork length) eat primarily Daphnia (Beauchamp 1990).

Although the bioenergetics model proved to be useful in comparing growth and consumption rates, $P$-values could be biased due to model error, sampling error, and size-selective mortality (Boisclair and Sirois 1993; Madon and Culver 1993). In our study, $P$-values exceeded 1.0 for one date interval, indicating some type of error. The model parameters were developed chiefly from data for sockeye salmon $O$. nerka, and many model parameters could be slightly different for rainbow trout. Beauchamp et al. (1989) found that a bioenergetics model for sockeye salmon gave robust estimates of consumption. Cochran and Knutsen (1988) found that using change in mean body mass to estimate food consumption rates with energetic models produced small error. We did modify the respiration rate function for rainbow trout. In a sensitivity analysis, Rice et al. (1983) found that the respiration function was the only parameter that produced a variation in output greater than $10 \%$ in a bioenergetics model for largemouth bass Micropterus salmoides.

Using $P$-values from the bioenergetics model as an index of fish consumption was advantageous in that this value represents the proportion of a fish's maximum consumption rate and is corrected for variation in fish body mass and water temperature. In the bioenergetics model, the differences in maximum digestion rate of fish of different mass at different temperatures are taken into account. Thus, the $P$-value in our analysis provides a measure of physiological rate computed over the greater than 10 -fold difference in body mass and $15^{\circ} \mathrm{C}$ temperature range of fish in our study. The significant relation of daphnid biomass to $P$-value is a suitable index of fish consumption.

Although the bioenergetics model predicted that rainbow trout were consuming less than their maximum ration for most of the year, earlier studies have shown that they often forage for only a small portion of the day (Tabor and Wurtsbaugh 1991; W. Wurtsbaugh, unpublished data). This suggests that the trout may not be fully exploiting the Daphnia prey base from the lakes. Threats of predation (Werner and Hall 1988) or a squeeze between optimal temperature and oxygen in the metalimnia may limit foraging and digestion and contribute to the moderate $P$-values we observed.

Size-selective mortality inflicted by piscivorous fish, birds, or anglers may also bias growth rates. Hargreaves and LeBrasseur (1986) found coho salmon $O$. kisutch were size-selective when prey- 
ing on chum salmon $O$. keta. For the first 3 months after stocking, juvenile rainbow trout in Causey and East Canyon reservoirs are vulnerable to adult cutthroat trout $O$. clarki and brown trout Salmo trutta (W. Wurtsbaugh and R. Tabor, unpublished data). Consequently, in our study, size-selective predation by piscivorous fish may have caused growth rates to be overestimated. In contrast, anglers may harvest a significant number of the larger rainbow trout from the stocked cohort, causing growth rates to be underestimated. We examined this possibility on one date (February 19, 1991) and found that mean weight of angler-caught fish was $12 \%$ greater than that of fish caught in variable-mesh gill nets (R. Tabor, unpublished data). The cohorts of rainbow trout used in our study were vulnerable to anglers during only the last 4 months of the study. Thus, anglers likely imposed a small error in our overall growth estimates.

Our results indicated that abundance of daphnids strongly influenced growth patterns of rainbow trout in two mid-elevation reservoirs in Utah. In these systems, large daphnids appear to be a preferred prey item; growth rates of rainbow trout declined when alternative prey composed a large portion of the diet. Fisheries managers could assess the biomass of daphnids to determine forage conditions for put-grow-and-take salmonid fisheries in other reservoir systems.

\section{Acknowledgments}

We thank the Utah Division of Wildlife Resources (UDWR) which provided funding for the project with Federal Aid in Sport Fish Restoration funds (F-47-R). J. Leppink and C. Bobo of UDWR assisted with stocking requests. The Utah Cooperative Fish and Wildlife Research Unit administered the project and provided equipment support. B. Konkle, L. Miranda, R. Wissmar, and three anonymous reviewers provided valuable suggestions for the manuscript. We especially thank D. Brandt for his help with the data analysis and field work. J. Moreno and H. Du analyzed the zooplankton samples. B. Allen, E. He, B. DeCino, and T. Shrader assisted with the field work.

\section{References}

Babey, G. J., and C. R. Berry, Jr. 1989. Post-stocking performance of three strains of rainbow trout in a reservoir. North American Journal of Fisheries Management 9:309-315.

Beauchamp, D. A. 1990. Seasonal and diel food habits of rainbow trout stocked as juveniles in Lake Washington. Transactions of the American Fisheries Society $119: 475-482$.
Beauchamp, D. A., D. J. Stewart, and G. L. Thoma 1989. Corroboration of a bioenergetics model fo sockeye salmon. Transactions of the American Fish. eries Society 118:597-607.

Boisclair, D., and P. Sirois. 1993. Testing assumption of fish bioenergetics models by direct estimation growth, consumption, and activity rates. Transac. tions of the American Fisheries Society 122:784. 796.

Busacker, G. P., I. R. Adelman, and E. M. Goolish. 1990 Growth. Pages 363-388 in C. B. Shreck and P. B. Moyle, editors. Methods for fish biology. American Fisheries Society, Bethesda, Maryland.

Carline, R. F. 1986. Indices as predictors of fish community traits. Pages 46-56 in G. E. Hall and M. J. Van Den Avyle, editors. Reservoir fisheries management: strategies for the 80's. American Fisheries Society, Southern Division, Reservoir Committee, Bethesda, Maryland.

Cochran, P. A., and K. J. Knutsen. 1988. Error in estimation of feeding rates from changes in mean body mass. Canadian Journal of Fisheries and Aquatic Sciences 45:1494-1498.

Confer, J. L., and five coauthors. 1978. Visual predation by planktivores. Oikos 31:27-37.

Cummins, K. W., and J. C. Wuycheck. 1971. Caloric equivalents for investigations in ecological energetics. Mitteilungen Internationale Vereinigung für theoretische und angewandte Limnologie 18.

Eggers, D. M. 1982. Planktivore preference by prey size. Ecology 63:381-390.

English, K. K. 1983. Predator-prey relationships for juvenile chinook salmon, Oncorhynchus tshawyts. cha, feeding on zooplankton in "in situ" enclosures. Canadian Journal of Fisheries and Aquatic Sciences 40:287-297.

Galbraith, M. G., Jr. 1967. Size-selective predation on Daphnia by rainbow trout and yellow perch. Transactions of the American Fisheries Society 96:1-10.

Galbraith, M. G., Jr. 1975. The use of large Daphnia as indices of fishing quality for rainbow trout in small lakes. Internationale Vereinigung für theoretische und angewandte Limnologie Verhandlungen 19:2485-2492.

Hargreaves, N. B., and R. J. LeBrasseur. 1986. Size selectivity of coho (Oncorhynchus kisutch) preying on juvenile chum salmon $(\boldsymbol{O}$. keta). Canadian Journal of Fisheries and Aquatic Sciences 43:581-586.

Hewett, S. W., and B. L. Johnson. 1987. A generalized bioenergetics model of fish growth for microcomputers. University of Wisconsin, Sea Grant Institute, Technical Report WIS-SG-87-245, Madison.

Hyatt, K. D. 1980. Mechanisms of food resource partitioning and the foraging strategies of rainbow trout (Salmo gairdneri) and kokanee (Oncorhynchus ner$\mathrm{ka}$ ) in Marion Lake, British Columbia. Doctoral dissertation. University of British Columbia, Vancouver.

Johannes, R. E., and P. A. Larkin. 1961. Competition for food between redside shiners (Richardsonius balteatus) and rainbow trout (Salmo gairdneri) in 
two British Columbia lakes. Journal of the Fisheries Research Board of Canada 18:203-220.

Kerr, S. R. 1971. Prediction of fish growth efficiency in nature. Journal of the Fisheries Research Board of Canada 28:809-814.

Luecke, C., and D. Brandt. 1993. Estimating the energy density of daphnid prey for use with rainbow trout bioenergetics models. Transactions of the American Fisheries Society 122:386-389.

Madon, S. P., and D. A. Culver. 1993. Bioenergetics model for larval and juvenile walleyes: an in situ approach with experimental ponds. Transactions of the American Fisheries Society 122:797-813.

Marine, K. R., W. A. Wurtsbaugh, N. Pace, and K. Christopherson. 1986. Effects of stocking stress on short term survival, long term survival, and growth of rainbow trout in a productive Utah reservoir. Proceedings Bonneville Chapter, American Fisheries Society 1986:133-143. (Utah Division of Wildlife, Salt Lake City.)

McCauley, E. 1984. The estimation of the abundance and biomass of zooplankton in samples. Pages 228265 in J. A. Downing and F. H. Rigler, editors. A manual on methods for assessment of secondary productivity in freshwater. Blackwell Scientific Publications, Oxford, UK.

Mills, E. L., and A. Schiavone, Jr. 1982. Evaluation of fish communities through assessment of zooplankton populations and measures of lake productivity. North American Journal of Fisheries Management 2:14-27.

Morgan, N. C., and 11 coauthors. 1980. Secondary production. Pages 247-340 in E. D. Le Cren and R. H. Lowe-McConnell, editors. The functioning of freshwater ecosystems. Cambridge University Press, Cambridge, UK.

O'Brien, J. W. 1979. The predator-prey interaction of planktivorous fish and zooplankton. American Scientist 67:572-581.

Phinney, D. E., D. M. Miller, and M. L. Dahlberg. 1967.
Mass-marking young salmonids with fluorescent pigment. Transactions of the American Fisheries Society 96:157-162.

Post, J. R., and D. J. McQueen. 1987. The impact of planktivorous fish on the structure of a plankton community. Freshwater Biology 17:79-89.

Rice, J. A., J. E. Breck, S. M. Bartell, and J. F. Kitchell. 1983. Evaluating the constraints of temperature, activity and consumption on growth of largemouth bass. Environmental Biology of Fishes 9:263-275.

Richman, S. 1958. The transformation of energy by Daphnia pulex. Ecological Monographs 28:273291.

Schneidervin, R. W., and W. A. Hubert. 1987. Diet overlap among zooplanktophagous fishes in Flaming Gorge Reservoir, Wyoming-Utah. North American Journal of Fisheries Management 7:379-385.

Tabor, R. A., and W. A. Wurtsbaugh. 1991. Predation risk and the importance of cover for juvenile rainbow trout in lentic systems. Transactions of the American Fisheries Society 120:728-738.

Vollenweider, R. A. 1976. Advances in defining critical loading levels for phosphorous in lake eutrophication. Memorie dell'Instituto Italiano di Idrobiologia Dott Marco de Marchi 33:53-83.

Ware, D. M. 1972. Predation by rainbow trout (Salmo gairdneri): the influence of hunger, prey density, and prey size. Journal of the Fisheries Research Board of Canada 29:1193-1201.

Werner, E. E., and D. J. Hall. 1988. The foraging ratepredation risk tradeoff and ontogenetic habitat shifts in the bluegill sunfish (Lepomis macrochirus). Ecology 69:1352-1366.

Wieser, W. 1985. Developmental and metabolic constraints of the scope for activity in young rainbow trout (Salmo gairdneri). Journal of Experimental Biology 118:133-142.

Wurtsbaugh, W. A., D. Bernard, and T. Pettingill. 1996. Exceptional fish yield in a mid-elevation Utah trout reservoir: effects of angling regulations. Great Basin Naturalist 56:12-21. 